\title{
EVALUASI SISTEM INFORMASI PENJUALAN DAN PIUTANG DAGANG PADA PT. LMY
}

\author{
Henny Hendarti; Leonard; Agus Thamrin; Yohanes \\ Jurusan Komputer Akuntasi, Fakultas Ilmu Komputer, Binus University \\ Jl. KH. Syahdan No. 9, Palmerah, Jakarta Barat 11480. \\ henny@binus.edu
}

\begin{abstract}
The purpose of this research is to evaluate and test the reliability of sales and accounts receivable information system of PT. LMY in order to help overcome the problems faced by the company. The methods used are literature review and field researches such as interviews, checked-question lists, observations and analysis. Audit around the Computer is used as the audit method. The evaluation results in some discoveries of the advantages and disadvantages of the sales and account receivable information systems used, where the disadvantages allow for the potential risks. The conclusion based on the obtained evaluation results on the control of information systems sales and accounts receivable company is that any improvement is still needed, especially on the control of security management as well as boundary. Thus, it is necessary for the company to do audits regularly on sales and account receivable information system so that the information system can be more reliable.
\end{abstract}

Keyword: evaluation, information system, sales, and account receivable.

\begin{abstract}
ABSTRAK
Tujuan penelitian ini ialah untuk mengevaluasi dan menguji keandalan sistem informasi penjualan dan piutang dagang PT. LMY agar dapat membantu mengatasi masalah-masalah yang dihadapi oleh perusahaan tersebut. Metode penelitian yang digunakan adalah studi kepustakaan dan studi lapangan seperti wawancara, checklist, observasi dan analisis. Metode audit yang digunakan adalah Audit Around the Computer. Hasil yang dicapai dari evaluasi ini adalah ditemukannya kelebihan dan kelemahan dari penggunaan sistem informasi penjualan dan piutang dagang, dimana kelemahan yang ada memungkinkan adanya potensi resiko. Simpulan berdasarkan hasil evaluasi yang telah diperoleh pada pengendalian sistem informasi penjualan dan piutang dagang perusahaan adalah bahwa masih perlunya perbaikan terutama pada pengendalian manajemen keamanan dan pengendalian boundary. Dengan demikian sangat penting bagi perusahaan melakukan audit terhadap sistem informasi penjualan dan piutang dagang secara berkala agar sistem informasi tersebut dapat lebih diandalkan.
\end{abstract}

Kata kunci: evaluasi, sistem informasi, penjualan dan piutang dagang. 


\section{PENDAHULUAN}

Tantangan dan persaingan yang semakin ketat mengharuskan perusahaan memiliki keunggulan daya saing untuk tujuan akhir dalam peningkatan performa perusahaan. Sistem Informasi saat ini menjadi suatu kebutuhan dasar bagi sebuah organisasi baik yang berskala besar maupun kecil. Hal ini dilakukan untuk meningkatkan daya saing, efisiensi, efektivitas serta peningkatan kinerja dari perusahaan. Untuk meningkatkan daya saing, efisiensi, efektivitas serta peningkatan kinerja kerja perusahaan, manajemen perlu menyusun suatu sistem informasi terutama dalam mendapatkan atau menghasilkan data dan informasi yang dibutuhkan oleh perusahaan khususnya di bidang penjualan. Dengan menggunakan sistem informasi perusahaan yang baik efisiensi dan efektivitas suatu perusahaan diharapkan dapat meningkat. Hal ini dapat diketahui melalui laporan-laporan, seperti laporan keuangan dan laporan kegiatan harian atau bulanan yang dilakukan setiap akhir hari kerja atau akhir bulan dan harus berisikan informasi mengenai seluruh kegiatan yang dilakukan. Sedangkan untuk mendapat data atau informasi yang baik dan terbaru, maka semua laporan yang dikirim kepada atasan harus berisi informasi yang dapat mencerminkan keadaan yang sebenarnya. Tetapi untuk mendapatkan data dan informasi yang akurat, diperlukan suatu sistem pengendalian intern yang baik dan dijalankan dengan benar. Dengan adanya pengendalian intern yang baik, diharapkan setiap bentuk tindakan penyelewangan yang akan atau sedang terjadi di perusahaan dapat dikurangi atau dapat dicegah sedini mungkin.

Untuk itu, diperlukan auditor yang dapat melaksanakan pemeriksaan secara independent terhadap seluruh transaksi atau kegiatan perusahaan yang ada dan kemudian dicocokkan atau disesuaikan dengan bukti yang ada dan biasanya dilakukan pada akhir periode atau akhir tahun, guna mengurangi dan menghambat kemungkinan terjadinya kesalahan atau kecurangan yang dapat mengganggu kelancaran kegiatan bisnis. Sehingga perusahaan dapat dengan cepat mengambil suatu sikap, tindakan dan keputusan yang tepat terhadap kecurangan atau penyelewengan yang terjadi. Selain mempertahankan kualitas produk yang ada, perusahaan juga harus memperhatikan kelancaran sistem yang mendukung kegiatan yang dilakukan perusahaan, sehingga perusahaan dapat mengetahui apakah sistem yang sudah ada itu telah efektif, efisien dan sesuai dengan keinginan perusahaan. Untuk mengetahui hal tersebut, maka perusahaan membutuhkan jasa seorang auditor untuk membantu melakukan evaluasi terhadap sistem yang sedang berjalan pada PT. LMY. Menyadari arti penting dari evaluasi sistem informasi bagi dunia usaha dan segala kemungkinan yang akan terjadi terhadap perkembangan dunia usaha dimasa yang akan datang, maka penulis tertarik untuk memaparkan evaluasi sistem informasi sebagai bidang konsentrasi penelitian dengan pokok permasalahan pada sistem informasi penjualan dan piutang dagang. Mengingat penjualan dan piutang dagang merupakan salah satu faktor penting bagi perusahaan untuk meningkatkan laba usaha dan sebagai sumber pendapatan, maka penulis berusaha mengangkat beberapa aspek penting yang terdapat pada bagian penjualan dan piutang dagang dalam suatu karya ilmiah atau penelitian melalui PT. LMY.

\section{Ruang Lingkup}

Evaluasi terhadap sistem informasi penjualan dan piutang dagang pada PT. LMY dilakukan pada pengendalian manajemen keamanan, pengendalian boundary, pengendalian input, dan pengendalian output.

\section{Tujuan dan Manfaat}

Adapun tujuan yang ingin dicapai dalam pembuatan tulisan ini adalah sebagai berikut: (1) Mengevaluasi penerapan pengendalian internal sistem informasi penjualan pada PT. LMY khususnya pada pengendalian manajemen keamanan, pengendalian boundary, pengendalian input, dan pengendalian output; (2) Mengidentifikasi kelemahan-kelemahan dari sistem informasi penjualan dan 
piutang dagang yang digunakan pada PT. LMY; (3) Memberikan rekomendasi untuk setiap kelemahan yang ditemukan di dalam sistem informasi dan menghasilkan laporan evaluasi bagi PT. LMY. Sedangkan manfaatnya: (1) Dapat meningkatkan pengendalian terhadap sistem komputerisasi, baik pengendalian manajemen maupun pengendalian aplikasi; (2) Dapat memberikan informasi kepada perusahaan mengenai kelemahan pada sistem informasi penjualan dan piutang dagang yang sedang berjalan sehingga dapat mengetahui sampai sejauh mana penerapan pengendalian intern pada sistem informasi penjualan dan piutang dagang; (3) Mengurangi kerugian yang ditimbulkan atau disebabkan oleh kelemahan-kelemahan yang berasal dari sistem informasi penjualan.

\section{METODE}

Metode penelitian yang digunakan oleh penulis dalam penelitian kali ini terbagi menjadi dua macam, yaitu: (1)Pengumpulan data yang meliputi studi pustaka dan studi lapangan - wawancara, observasi, checked-question lists, dan analisis; (2)Audit - penulis menggunakan metode Audit around the Computer dimana penulis menelaah pada struktur pengendalian perusahaan.

\section{Landasan Teori}

\section{Pengertian Sistem Informasi}

Laudon dan Jane Laudon (2004, p.8) menyatakan bahwa sistem informasi adalah relasi dalam komponen yang bekerjasama untuk mengumpulkan, memproses, menyimpan dan menyebarkan informasi untuk mendukung pengambilan keputusan, koordinasi, analisis dan visi dalam organisasi.

\section{Pengertian Audit}

Menurut Arens dan Loebbecke (2000, p.1), "Auditing adalah proses pengumpulan dan pengevaluasian bahan bukti tentang informasi yang dapat diukur mengenai suatu entitas ekonomi yang dilakukan seorang yang kompeten dan independen untuk dapat menentukan dan melaporkan kesesuaian informasi dimaksud dengan kriteria yang telah ditetapkan."

\section{Pengertian Audit Sistem Informasi}

Menurut Weber (1999, p.10), “Audit sistem informasi adalah proses pengumpulan dan pengevaluasian bukti-bukti untuk memutuskan apakah dengan adanya sistem pengamanan aset yang berbasis komputer dan pemeliharaan integritas data, data dapat mendukung perusahaan untuk mencapai tujuannya secara efektif dan penggunaan sumber daya secara efisien serta mengetahui apakah suatu perusahaan memiliki pengendalian intern yang memadai."

\section{Tahapan Audit Sistem Informasi}

Menurut Weber (1999, pp.47-55), "Tahapan-tahapan audit sistem informasi terdiri dari: (1) planning the audit 'perencanaan audit', (2) tests of controls 'pengujian atas kontrol', (3) tests of transactions 'pengujian atas transaksi', (4) tests of balance or overall results pengujian atas keseimbangan atau hasil keseluruhan', (5) completion of the audit 'penyelesaian audit'."

\section{Metode Audit Sistem Informasi}

Menurut Gondodiyoto (2003, pp.155-159), "Dalam melakukan audit sistem informasi dapat dilakukan dengan tiga pendekatan: (1) audit around the computer 'audit di sekitar komputer'; (2) audit through the computer 'audit melalui komputer'; (3) audit with the computer 'audit dengan komputer'." 


\section{Pengertian Sistem Pengendalian Intern}

Mulyadi (2002, p.180) mendefinisikan sistem pengendalian intern sebagai suatu proses yang dijalankan oleh dewan komisaris, manajemen dan personil lain yang didesain untuk memberikan keyakinan memadai tentang pencapaian golongan tujuan berikut ini: kehandalan laporan keuangan, kepatuhan terhadap hukum dan peraturan yang berlaku, efektivitas dan efisiensi operasi.

\section{Jenis-jenis Pengendalian Intern}

Pertama, pengendalian umum (general control). Menurut Gondodiyoto (2006, p252), pengendalian umum (general controls) ialah sistem pengendalian internal komputer yang berlaku umum meliputi seluruh kegiatan komputerisasi sebuah organisasi secara menyeluruh. Pengendalian umum terdiri dari pengendalian top manajemen (top management controls), pengendalian manajemen pengembangan sistem (system development management controls), pengendalian manajemen sumber data (Data resources management controls), pengendalian manajemen kualitas (Quality assurance management controls), pengendalian manajemen operasi (Operations management controls), dan pengendalian manajemen keamanan (Security administration management controls). Kedua, pengendalian aplikasi. Menurut Gondodiyoto (2006, p328), pengendalian aplikasi adalah sistem pengendalian intern pada sistem informasi berbasis teknologi informasi yang berkaitan dengan pekerjaan / kegiatan / aplikasi tertentu. Pengendalian aplikasi pada dasarnya terdiri dari pengendalian batas-sistem (boundary controls), pengendalian masukan (input controls), pengendalian proses pengolahan data (process controls), pengendalian keluaran (output controls), pengendalian file / database (file / database controls), dan pengendalian komunikasi aplikasi (communication controls) (Gondodiyoto, 2006, p.329).

\section{Pengertian Sistem Penjualan}

Sistem informasi penjualan adalah unsur-unsur yang saling berkaitan satu sama lain yang bekerjasama untuk mengumpulkan, meng-input, memproses, mengeluarkan serta mendistribusikan data mengenai penjualan.

\section{Fungsi yang Terkait dengan Penjualan Kredit}

Fungsi yang terkait dalam sistem penjualan kredit menurut mulyadi (2001, pp.211-213) adalah fungsi penjualan, fungsi kredit, fungsi gudang, fungsi pengiriman, fungsi penagihan, dan fungsi akuntansi.

\section{Jaringan Prosedur yang Membentuk Sistem}

Jaringan prosedur yang membentuk sistem penjualan kredit menurut Mulyadi (2001, pp219220) adalah prosedur order penjualan, prosedur persetujuan kredit, prosedur pengiriman, prosedur penagihan, prosedur pencatatan piutang, dan prosedur distribusi penjualan.

\section{Piutang Dagang}

Menurut Niswonger (1999, p323), "Piutang adalah semua klaim dalam bentuk uang terhadap entitas lainnya, termasuk individu, perusahaan atau organisasi lainnya."

\section{HASIL DAN PEMBAHASAN}

\section{Analisis Sistem Yang Berjalan}




\section{Prosedur yang Berjalan pada Perusahaan}

Jaringan prosedur yang membentuk sistem penjualan dan piutang dagang pada PT. LMY adalah sebagai berikut: (1) Siklus penjualan dan piutang dagang pada PT. LMY dimulai dari penerimaan permintaan harga dari pelanggan melalui fax ke bagian marketing; (2) Bagian marketing akan menyiapkan surat penawaran harga berdasarkan daftar riwayat piutang konsumen yang berisi saldo piutang konsumen dan payment terms (riwayat pembayaran piutang) untuk diajukan ke General Manager untuk diminta persetujuannya; (3) Setelah mendapat persetujuan dari General Manager, bagian marketing akan mem-fax surat penawaran harga kepada pelanggan; (4) Pelanggan akan memfax Purchase Order (PO) kepada bagian marketing. Bagian Marketing akan mengeluarkan Surat Pemesanan Barang (SPB) berdasarkan PO sebanyak 3 rangkap: rangkap 1 untuk bagian logistic, rangkap 2 untuk bagian finance and accounting, dan rangkap 3 untuk diarsipkan oleh bagian marketing; (5) Bagian Marketing juga membuat Delivery Order (DO) berdasarkan PO sebanyak 4 rangkap: rangkap 1 untuk bagian Pelanggan, rangkap 2 untuk bagian Finance and Accounting, rangkap 3 untuk bagian Logistic, dan rangkap 4 untuk diarsip oleh bagian Marketing; (6) DO rangkap ke-1,2,3 diberikan ke bagian logistic untuk menyiapkan barang. Kemudian bagian Delivery akan mengirimkan barang beserta DO rangkap 1, 2, dan 3. Pelanggan akan menerima DO 1 sedangkan DO 2 dan 3 dikembalikan kepada bagian logistic dimana DO rangkap 3 akan diarsip oleh berdasarkan nomor urut. DO rangkap 2 diberikan ke bagian Finance and Accounting; (7) DO rangkap 2 yang telah ditandatangani oleh Pelanggan diberikan kepada bagian Finance and Accounting untuk meng-input dan mencetak faktur sebanyak 3 rangkap dan Faktur Pajak: Rangkap 1 untuk Pelanggan, rangkap 2 untuk Bagian Penagihan, rangkap 3 untuk Bagian Finance and Accounting; (8) Faktur rangkap 3 oleh bagian Finance and Accounting akan dijadikan sebagai bukti penagihan kepada pelanggan; (9) Berdasarkan faktur rangkap 2 dan faktur pajak rangkap 2, bagian penagihan akan melakukan penagihan piutang kepada pelanggan, kemudian akan diarsip berdasarkan nomor urut; (10) Setelah menerima uang, bagian Finance and Accounting akan membubuhkan tanda lunas pada faktur dan faktur pajak rangkap 3. Kemudian akan diarsip berdasarkan nomor urut; (11) Pada setiap akhir bulan bagian Finance and Accounting akan mencetak laporan penjualan dan piutang konsumen.

\section{Prosedur Retur Penjualan}

Berikut prosedur retur penjualan PT. LMY: (1)Barang tidak bisa diretur bila barang sudah tiba di tempat pelanggan, jadi perusahaan hanya menerima retur ketika barang diantar di tempat dan tidak menerima retur setelah itu; (2)Jika barang yang diterima oleh pelanggan rusak atau cacat, maka bagian delivery akan mencatat jumlah barang yang di retur beserta alasannya dalam DO yang telah ditandatangani oleh konsumen; (3)Bagian Delivery akan menyerahkan DO tersebut kepada bagian Finance and Accounting, kemudian Bagian financeland accounting akan menginput retur ke dalam sistem aplikasi; (4)Pada setiap akhir bulan bagian finance and Accounting akan mencetak laporan retur . Jika tidak terdapat retur maka laporan retur tidak akan dicetak.

\section{Dokumen yang Digunakan}

Dokumen-dokumen yang digunakan pada sistem penjualan yang digunakan adalah Surat Penawaran Harga, Surat Pemesanan Barang, Delivery Order, Faktur, dan Faktur Pajak.

\section{Evaluasi Sistem Informasi Penjualan Dan Piutang Dagang}

Hasil evaluasi sistem informasi penjualan dan piutang dagang adalah sebagai berikut: (1) Tidak adanya batasan limit kredit terhadap pelanggan dalam transaksi sistem penjualan dan piutang dagang; (2) Belum ada dokumen untuk mencatat terjadinya retur penjualan; (3) Tidak ada dokumen untuk mencatat terjadinya penerimaan kas. 
Hasil checklist pengendalian manajemen keamanan adalah: (1) Tidak terdapat alarm kebakaran otomatis dalam gedung perusahaan; (2) Tidak terdapat kamera pengawas dalam (CCTV) dalam gedung perusahaan; (3) Tidak terdapat UPS dalam gedung perusahaan.

Hasil checklist pengendalian boundary adalah: (1) Tidak terdapat penggantian password secara rutin; (2) Tidak terdapat batas pengisian password bila terjadi kesalahan; (3) Tidak terdapat peringatan (error message) bila user salah mengisi password; (4) Tidak terdapat fasilitas untuk membantu user yang melupakan password.

Hasil checklist pengendalian input yaitu sistem aplikasi tidak dilengkapi dengan help-facility untuk membantu user dalam melakukan peng-input-an data.

Hasil checklist pengendalian output yaitu: (1) Tidak terdapat nomor halaman dan batas akhir halaman dari tiap laporan yang dihasilkan perusahaan; (2) Tidak terdapat masa berlaku laporan.

\section{PENUTUP}

Berikut simpulan yang didapat dari hasil evaluasi: (1) Di dalam sistem penjualan dan piutang dagang masih terdapat kelemahan dengan tidak adanya batas limit kredit; (2) Tingkat keyakinan pengendalian manajemen keamanan sudah cukup, walaupun masih terdapat adanya kekurangan seperti tidak adanya alarm kebakaran otomatis untuk mendeteksi kebakaran, tidak terdapat kamera pengawas (CCTV), dan tidak ada UPS; (3) Pada pengendalian boundary, tingkat keyakinan pengendaliannya adalah cukup walaupun masih terdapat adanya kekurangan seperti tidak adanya penggantian password secara rutin, tidak terdapat batas pengisian password bila terjadi kesalahan, tidak terdapat peringatan (error message) bila user salah mengisi password, dan tidak terdapat fasilitas untuk membantu user yang melupakan password.; (4) Pada pengendalian input, tingkat keyakinan pengendaliannya adalah baik, namun masih terdapat kekurangan yakni tidak adanya help-facility untuk membantu user dalam melakukan peng-input-an data; (5) Pengendalian output juga telah berjalan baik. Terbukti setiap laporan hanya dapat dicetak oleh pihak berwenang. Laporan hanya akan dibuat ketika pihak yang berwenang melakukan permintaan, misalnya direktur hanya akan meminta laporan penjualan dan piutang dagang di akhir bulan. Terdapat sedikit kelemahan pada pengendalian output yaitu tidak terdapat nomor halaman dan batas akhir halaman pada laporan dan tidak terdapat masa berlakunya; (6) Berdasarkan hasil survei, penulis dapat menyimpulkan bahwa secara keseluruhan kekurangan dan kelemahan manajemen perusahaan masih dapat diatasi dan ditangani dengan menggunakan sistem yang berjalan pada perusahaan saat ini namun demikian, menurut penulis masih perlu adanya perbaikan dan penyempurnaan dari sistem informasi yang sedang berjalan.

\section{DAFTAR PUSTAKA}

Arens, Alvin A., Loebbecke, James K. (2000). Auditing an Integrated Approach, (8 ${ }^{\text {th }}$ ed.). New Jersey: Prentice Hall.

Blog Ini File Q. (2006). Evaluasi. Diakses dari http://dokumens.multiply.com/journal/item/34.

Gondodiyoto, S. (2003). Audit Sistem Informasi: Pendekatan Sistem. Jakarta: Media Global Edukasi.

Gondodiyoto, S., Hendarti, H. (2006). Audit Sistem Informasi. Jakarta: Mitra Wacana Media. 
Laudon, Jane P., Laudon, Kenneth C. (2004). Management Information System, (8 ${ }^{\text {th }}$ ed.). New Jersey: Prentice Hall.

Mulyadi. (2001). Sistem Akuntansi, edisi ke-3. Salemba Empat: Jakarta.

Mulyadi. (2002). Auditing, edisi ke-6. Salemba Empat: Jakarta.

Niswonger, C. R., Warren, C.S., Reeve, J.M., Fees, P.E. (1999). Prinsip-Prinsip Akuntansi, jilid 2, edisi ke-19. (A. Sirait dan H. Gunawan, Terj.). Erlangga, Jakarta.

Weber, Ron. (1999). Information System Control and Audit. New Jersey: Prentice Hall. 